ARTICLE

https://doi.org/10.1038/s41467-020-18934-3

\title{
Global warming due to loss of large ice masses and Arctic summer sea ice
}

\author{
Nico Wunderling (10) ${ }^{1,2,3 凶}$, Matteo Willeit ${ }^{1}$, Jonathan F. Donges (10) 1,4 \& Ricarda Winkelmann (1) ${ }^{1,2}$
}

Several large-scale cryosphere elements such as the Arctic summer sea ice, the mountain glaciers, the Greenland and West Antarctic Ice Sheet have changed substantially during the last century due to anthropogenic global warming. However, the impacts of their possible future disintegration on global mean temperature (GMT) and climate feedbacks have not yet been comprehensively evaluated. Here, we quantify this response using an Earth system model of intermediate complexity. Overall, we find a median additional global warming of $0.43{ }^{\circ} \mathrm{C}$ (interquartile range: $0.39-0.46^{\circ} \mathrm{C}$ ) at a $\mathrm{CO}_{2}$ concentration of $400 \mathrm{ppm}$. Most of this response $(55 \%)$ is caused by albedo changes, but lapse rate together with water vapour (30\%) and cloud feedbacks (15\%) also contribute significantly. While a decay of the ice sheets would occur on centennial to millennial time scales, the Arctic might become ice-free during summer within the 21st century. Our findings imply an additional increase of the GMT on intermediate to long time scales.

\footnotetext{
${ }^{1}$ Earth System Analysis, Potsdam Institute for Climate Impact Research (PIK), Member of the Leibniz Association, Potsdam D-14473, Germany. ${ }^{2}$ Institute of Physics and Astronomy, University of Potsdam, Potsdam D-14476, Germany. ${ }^{3}$ Department of Physics, Humboldt University of Berlin, Berlin D-12489, Germany. ${ }^{4}$ Stockholm

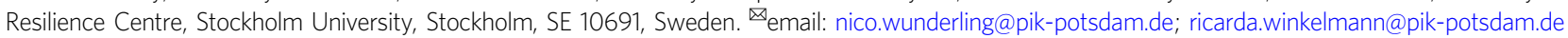


E xtensive changes have been observed in large-scale cryosphere elements during the last decades such as the Arctic summer sea ice, mountain glaciers, the Greenland and West Antarctic Ice Sheet ${ }^{1-5}$.

From the late 1970s to the mid-2000s, the Arctic summer sea ice area has declined by more than $10 \%$ per decade, as satellite measurements reveal ${ }^{1}$. If this trend continues, the Arctic could become ice-free in summer for the first time within the 21st century. Projections with CMIP-5 ${ }^{6}$ (Coupled Model Intercomparison Project Phase 5) models show that this could be the case as early as 2030 to 2050 for higher emission scenarios such as RCP8.5 (Representative Concentration Pathway) ${ }^{7}$. Some GCMs (global circulation models) show an ice-free Arctic for the first time within this century also for the moderate emission scenarios at a warming of $1.7^{\circ} \mathrm{C}$ above pre-industrial ${ }^{8,9}$. Furthermore, observations reveal that the Arctic summer sea ice declines faster than expected in experiments from $\mathrm{GCMs}^{1}$.

At the same time, mountain-glaciers world-wide have retreated, with an average weight equivalent ice loss of approximately $250 \pm 30 \mathrm{Gt}$ per year between 1901 and 20092,10. This translates, in the same time span, into a loss of $21 \%$ of the glaciated volume of mountain glaciers worldwide, excluding (Sub-) Antarctic peripheral glaciers, as found in model simulations ${ }^{11}$. During this time, it is estimated that approximately 600 glaciers have disappeared and many more are likely to follow in the future (IPCC-AR5, Chapter $4^{6}$ ). $36 \pm 8 \%$ of today's glacier mass is already committed to be lost in response to past greenhouse gas emissions $^{12}$ and it has been found that many mountain glaciers are currently in disequilibrium and will be subject to further ice loss ${ }^{13}$.

Moreover, both the West Antarctic and the Greenland Ice Sheet have lost mass at an accelerating pace in the past decades ${ }^{3-5}$. With progressing global warming, ice loss from the polar ice sheets and subsequent sea-level rise is expected to further increase ${ }^{14,15}$. Beyond a critical temperature threshold, large parts of the Greenland Ice Sheet might melt, accelerated by positive feedbacks such as the ice-albedo and melt-elevation feedbacks ${ }^{16,17}$. From model simulations, this threshold temperature is suggested to range between 0.8 and $3.2^{\circ} \mathrm{C}$ above pre-industrial levels ${ }^{18}$.

Parts of the West Antarctic Ice Sheet might already have crossed a point of instability: the grounding lines of several glaciers in the Amundsen basin are rapidly retreating and have likely become unstable, causing sustained ice discharge from the entire basin which could lead to more than $1 \mathrm{~m}$ of global sea-level rise ${ }^{19}$. Similar dynamics might be induced in other parts of the Antarctic Ice Sheet and could eventually lead to its complete disintegration under unmitigated climate change ${ }^{20}$.

Anthropogenic climate change has already caused a rise in global mean temperature (GMT) by $0.9^{\circ} \mathrm{C}$ comparing $1850-1900$ to $2006-2015^{21}$, with observable impacts on the cryosphere elements mentioned above ${ }^{6}$. It has also been suggested that these regions are likely to change dramatically with ongoing climate warming and some of these changes are suspected to possess some degree of irreversibility 22,23 .

Following these recent developments of the cryosphere components, it seems possible that they might be lost at lower temperatures than commonly thought, potentially as low as $1.5^{\circ} \mathrm{C}$ above pre-industrial levels ${ }^{23}$. The disintegration of these elements is associated with feedbacks that impact back on GMT, for instance via a change in albedo, clouds or lapse rate, among others, which has not been quantified comprehensively so far. Therefore, we assess the additional global warming caused by disintegration of the Greenland Ice Sheet, the West Antarctic Ice Sheet, the mountain glaciers and the Arctic summer sea ice. Although the Arctic summer sea ice is implemented in more complex Earth system models and its loss part of their simulation results (e.g. in CMIP-5), it is one of the fastest changing cryosphere elements whose additional contribution to global warming is important to be considered. Therefore, we compute and separate its contribution to GMT increase. On the other side, the temperature feedbacks of ice sheets like Greenland, West Antarctica and mountain glaciers are not yet fully integrated in assessments such as CMIP-5.

We base our simulations on the Earth system model of intermediate complexity, CLIMBER-2 $2^{24,25}$ because it is computationally efficient and allows a systematic analysis of the decay of the cryosphere components. CLIMBER-2 includes atmosphere, ocean, sea ice, vegetation and land-ice model components and has been applied extensively to understand past and future climate changes ${ }^{26,27}$.

In large ensembles of equilibrium model simulations, constrained by fast climate feedbacks strength from global circulation models $^{28}$ (see "Methods"), we compare the long-term GMT change in idealised scenarios, where the cryosphere elements are removed, to scenarios where they remain intact. The uncertainty in the additional warming in our simulations is constrained by the uncertainty of the feedback strength in the GCM simulations which we used to mimic the more complex behaviour of $\mathrm{GCMs}^{28}$ (Supplementary Fig. 1). To change the feedback strengths, we alter CLIMBER-2 model parameters that act on the strength of the feedbacks themselves, particularly in the structure of the troposphere and the clouds (atmospheric changes) as well as in the snow albedo (see Supplementary Table 1). With reasonably altered parameters in CLIMBER-2, we arrive at an equilibrium climate sensitivity of $2.0-3.75^{\circ} \mathrm{C}$ for our ensemble leading to smaller temperature responses than the full range from CMIP-5 $\left(2.0-4.7^{\circ} \mathrm{C}\right)$ or CMIP-6 $\left(1.8-5.6^{\circ} \mathrm{C}\right)$ would ${ }^{29}$. Details on the calibration process are given in the methods section: uncertainty estimates.

In our experiments the state of the Greenland Ice Sheet, the West Antarctic Ice Sheet and mountain glaciers is simply prescribed in the model and affects both, ice cover and topography. In our simulations for the Arctic summer sea ice, the albedo during the summer months (June, July, August) is lowered to average values for open ocean waters instantaneously similar to Blackport and Kushner ${ }^{30}$, while keeping the computation of icecovered areas dynamic, such that the experiment does not violate energy and water conservation.

In this study, we find that global warming is amplified by the decay of the Earth's cryosphere as expected from theory and quantify the contribution of each of the four cryosphere components. We further separate the GMT response into contributions from albedo, lapse rate, water vapour and clouds in terms of perturbation of the net radiation at the top of the atmosphere ${ }^{31}$. Here, we focus on the purely radiative effects and neglect freshwater contributions to feedbacks and warming. Thus, our estimates are long-term equilibrium responses when the large ice masses are disintegrated. However, transient warming responses would be reduced due to freshwater input from the West Antarctic and Greenland Ice Sheet on centennial time-scales ${ }^{32-35}$.

\section{Results}

Additional global and regional warming. We consider several different climate scenarios, with atmospheric $\mathrm{CO}_{2}$ concentrations ranging from the pre-industrial $280 \mathrm{ppm}$ up to $700 \mathrm{ppm}$ and run the model forward until it reaches equilibrium. If not stated otherwise, our findings are shown for a reference simulation at a fixed $\mathrm{CO}_{2}$ concentration of $400 \mathrm{ppm}$ in equilibrium after 10,000 years. $400 \mathrm{ppm}$ corresponds to an equilibrium GMT increase of $1.5^{\circ} \mathrm{C}$ above pre-industrial in CLIMBER-2 simulations. Upon this, we evaluate the additional regional and global warming 
caused by the large-scale loss of the Arctic sea ice during summer, mountain glaciers, and the polar ice sheets. While this ad-hoc loss of the ice masses poses a hypothetical scenario, it allows us to separate the additional warming through the ice-climate feedbacks from other effects. In our experiments, we report the median value of the ensemble and the brackets represent the interquartile range unless stated otherwise.

In our simulations, we find that global warming is increased by the decay of the Earth's cryosphere. The disintegration of the Arctic summer sea ice and the retreat of mountain glaciers, the Greenland and the West Antarctic Ice Sheets together cause an additional GMT increase of $0.43^{\circ} \mathrm{C}\left(0.39-0.46^{\circ} \mathrm{C}\right)$ for a baselinescenario of $1.5^{\circ} \mathrm{C}$ warming above pre-industrial levels, which translates into an additional warming of $29 \%$ (26-31\%).

Locally, the loss of each element induces a very strong warming signal, which is consistent with previous studies on polar and Arctic amplification ${ }^{36,37}$. Local warming around the cryosphere components is up to $5^{\circ} \mathrm{C}$ stronger, particularly around Greenland and West Antarctica (Fig. 1a). However, the ice loss causes significant warming also in lower latitudes, with values of $0.2^{\circ} \mathrm{C}$ around the equator.

The warming results from our simulations are consistent in magnitude and polar amplification with past warm periods, particularly the Mid-Pliocene Warm Period, during which the large ice sheets were at least partially disintegrated ${ }^{38,39}$. Still, the distribution among the feedback processes in these paleoclimate states remains uncertain.

Under ongoing global warming, further ice loss is to be expected for all of the four cryosphere components considered here; however, the corresponding time scales differ by several orders of magnitude. While substantial ice loss from Greenland or Antarctica might be triggered by anthropogenic climate change within the current century, these changes would manifest over several centuries to millennia ${ }^{15}$. Ice-free Arctic summers on the other side might already occur in the next decades ${ }^{1,7,9}$. Therefore, we also consider the regional warming caused solely by the loss of the Arctic summer sea ice (Fig. 1b). The additional warming in the Arctic region on a yearly average accounts for more than $1.5^{\circ}$ $\mathrm{C}$ regionally and for $0.19^{\circ} \mathrm{C}$ globally. The meltdown of the Arctic sea ice and its regional warming effect is also simulated by CMIP5 runs dependent on the future anthropogenic $\mathrm{CO}_{2}$ forcing scenarios, the RCP scenarios ${ }^{6,9}$.

With CLIMBER-2, we are able to distinguish between the respective cryosphere elements and can compute the additional warming resulting from each of these (Fig. 2). The additional warmings are $0.19^{\circ} \mathrm{C}\left(0.16-0.21{ }^{\circ} \mathrm{C}\right)$ for the Arctic summer sea ice, $0.13{ }^{\circ} \mathrm{C}\left(0.12-0.14^{\circ} \mathrm{C}\right)$ for GIS, $0.08{ }^{\circ} \mathrm{C}\left(0.07-0.09^{\circ} \mathrm{C}\right)$ for mountain glaciers and $0.05^{\circ} \mathrm{C}\left(0.04-0.06^{\circ} \mathrm{C}\right)$ for WAIS, where the values in brackets indicate the interquartile range and the main value represents the median. If all four elements would disintegrate, the additional warming is the sum of all four individual warmings resulting in $0.43{ }^{\circ} \mathrm{C}\left(0.39-0.46^{\circ} \mathrm{C}\right)$ (thick dark red line in the Fig. 2). Our results regarding the amount of warming are of comparable magnitude to previous efforts computed for late Pliocene realisations (PRISM) of the ice sheets ${ }^{40,41}$. Both studies show a pronounced warming in the proximity of the locations where ice is removed, which is in good agreement with our results (see Fig. 1 and Supplementary Fig. 2).

a

Additional warming due to loss of ASSI, MG, GIS and WAIS
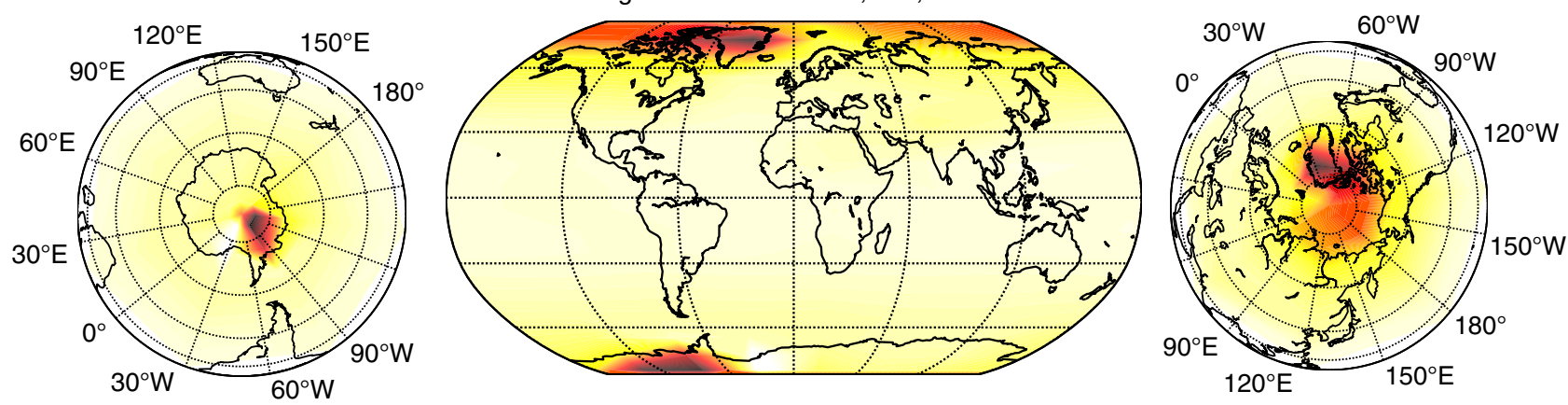

b Additional warming due to loss of ASSI
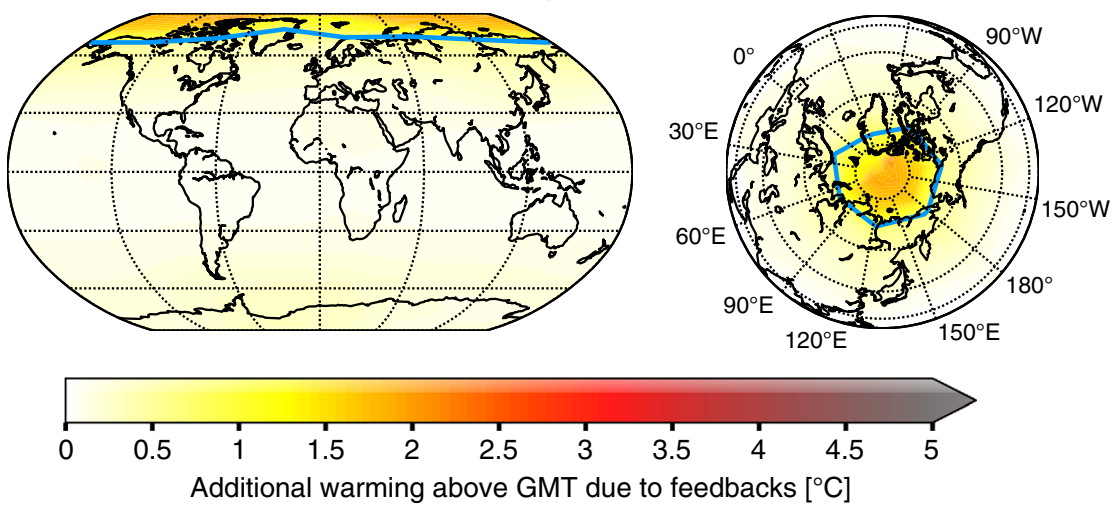

Fig. 1 Regional warming due to feedbacks. a Regional warming for the whole Earth if Arctic summer sea ice (ASSI) in June, July and August, mountain glaciers (MG), Greenland Ice Sheet (GIS) and West Antarctic Ice Sheet (WAIS) vanish at a global mean temperature of $1.5^{\circ} \mathrm{C}$ above pre-industrial. b Same as in (a) with an additional zoom-in of the Arctic region if only the Arctic summer sea ice vanishes, which might happen until the end of the century. The light blue line indicates the region of removed Arctic summer sea ice extent, where its concentration in CLIMBER-2 is $15 \%$ or higher. In all panels, the average additional warming on top of $1.5^{\circ} \mathrm{C}$ is shown in absolute degree. 
The disintegration of all elements at the same time can very closely be approximated by the sum of single elements disintegrated indicating that their effects on GMT add up linearly. This can be found in Fig. 3, where we also show the warming for $\mathrm{CO}_{2}$ concentrations from 280 to 700 ppm. Fig. 2 highlights the additional warming of $1.5^{\circ} \mathrm{C}$ above pre-industrial.

Warming from the Arctic summer sea ice. We obtain that the warming results are independent from the $\mathrm{CO}_{2}$ concentration

\section{Additional global warming commitment due to ice loss}

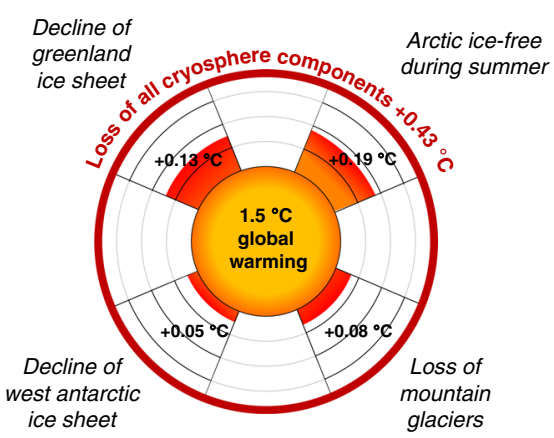

Fig. 2 GMT increase through disappearance of cryosphere elements. The additional warming for the cryosphere components is shown for a scenario consistent with global warming levels of $1.5^{\circ} \mathrm{C}$. Radially outward, the temperature anomaly is displayed which arises from the disappearance of the cryosphere elements. The thick dark red line indicates the maximum effect of additional warming in case all cryosphere elements lose stability. All values are the medians of the ensemble. forcing between 280 and 700 ppm apart from the Arctic summer sea ice (see Fig. 3a), which shows a decreasing additional warming for higher $\mathrm{CO}_{2}$ concentrations (Fig 4). This can, in turn, be explained: In CLIMBER-2 simulations we find, with increasing prescribed $\mathrm{CO}_{2}$ concentrations corresponding to increasing GMT, that the Arctic summer sea ice area declines in a linear way, which was also found in observational records ${ }^{42}$ and in GCM simulations ${ }^{9}$. For a $\mathrm{CO}_{2}$ concentration of $400 \mathrm{ppm}$ corresponding to $1.5^{\circ} \mathrm{C}$ in CLIMBER-2 above pre-industrial GMT levels, the additional warming is $0.19^{\circ} \mathrm{C}\left(0.16-0.21^{\circ} \mathrm{C}\right)$. The actual minimal sea ice cover observed by NERSC (Nansen Environmental \& Remote Sensing Center) as an average area from 1979 to 2006 is on the order of $5.5-6.5 \times 10^{6} \mathrm{~km}^{2}$ which would correspond to a warming of approximately $0.15^{\circ} \mathrm{C}$ in our simulations (see Fig. 4). In Supplementary Fig. 3, we show the sea ice area over the course of 1 year for the control and the perturbed run.

Radiative perturbations at the top of the atmosphere. For each cryosphere element, we are able to deconvolve the net change of radiative perturbations at the top of the atmosphere into several components that affect the radiative balance of the Earth: water vapour, clouds, lapse rate and albedo. These factors can be quantified in CLIMBER-2 (Table 1).

The values for water vapour, lapse rate and clouds in Table 1 can to a very good approximation directly be interpreted as feedback factors once they are divided by the respective warming, e.g., by $0.43{ }^{\circ} \mathrm{C}$ in case all investigated cryosphere elements are removed. However, it is important to note that the perturbation arising from albedo changes is both, a forcing and a feedback. The forcing component originates from the prescribed removal of the cryosphere elements. On the other side, the feedback component

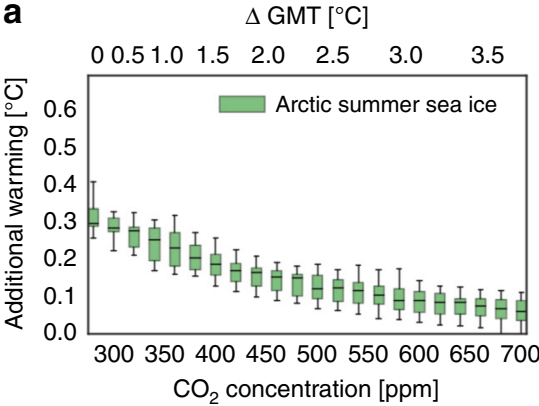

d

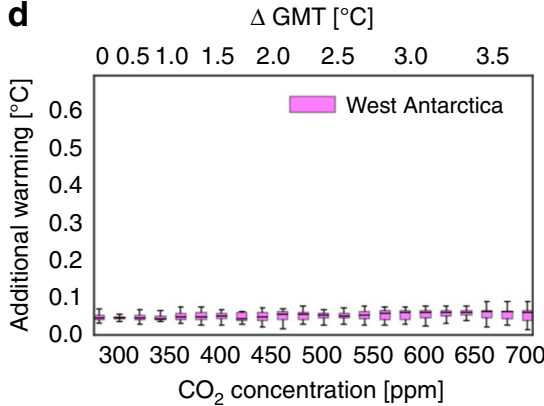

b

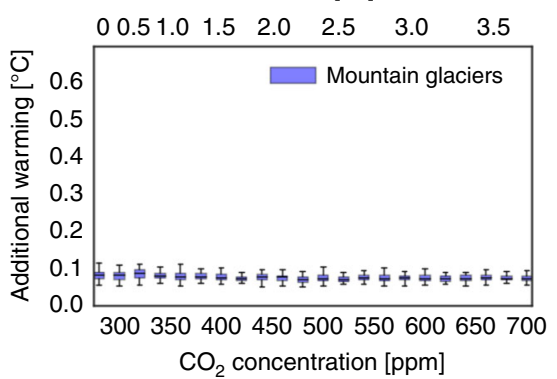

e

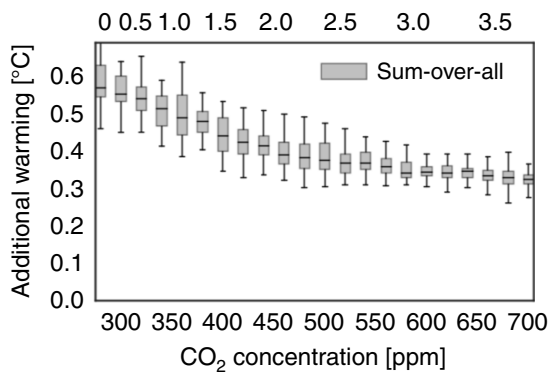

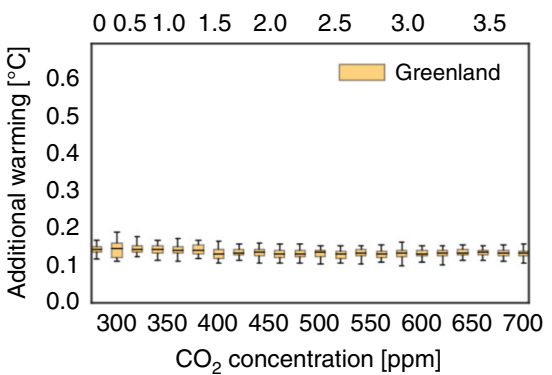

f

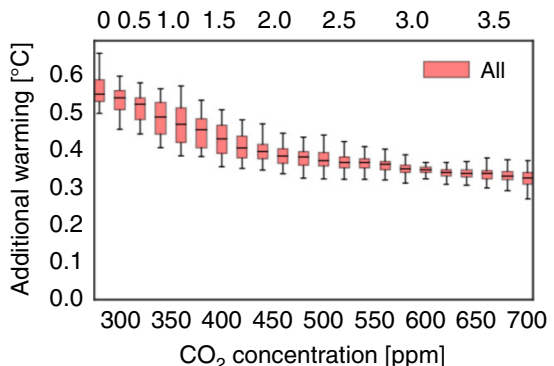

Fig. 3 Linearity of additional warming due to disintegration of cryosphere elements. Additional warming plotted against $\mathrm{CO}_{2}$ concentration. Disintegration of of cryosphere components separately for (a) the Arctic summer sea ice, (b) the mountain glaciers, (c) the Greenland Ice Sheet, (d) the West Antarctic Ice Sheet, (e) the sum of all additional warmings from the separately disintegrated cryosphere elements and (f) the disintegration of all four elements at the same time. The grey bars match the red bars within their errors which means, according to CLIMBER-2, that the warming effect of singular disintegrated cryosphere elements can linearly be added up to the effect of all four elements disintegrated at the same time. Here we show median, interquartile range and full ensemble spread for each $\mathrm{CO}_{2}$ concentration. The upper horizontal axis shows the temperature increase above pre-industrial, where a least-square fit converting $\mathrm{CO}_{2}$ concentration to temperature with python's function scipy.optimize.curve_fit was used. The respective fitted temperatures arise from full ensemble simulations at prescribed $\mathrm{CO}_{2}$ concentrations, but without removed cryosphere elements. 
derives from responses of the surface albedo to the additional warming as for instance through changes in the extent of snow covered area or changes in vegetation cover. Thus both, the feedback and the forcing contribute to the measured radiative perturbation quantified in Table 1.

Change in surface albedo is the dominant additional radiative perturbation for each considered cryosphere element. It is mainly caused by the albedo change of large ice-covered areas from ice to other non ice-covered surface types, but also by other land cover changes. In total around $55 \%$ of the radiative perturbations can be attributed to the change of the albedo.

Two more additional radiative perturbations which are evaluated together as they are anti-correlated are the lapse rate and the water vapour fast climate feedback ${ }^{28,31}$. The lapse rate change arises from non-uniform temperature changes in the vertical atmospheric column and subsequent changes in outgoing longwave radiation. The water vapour change describes the capacity of the air to sustain water vapour in the air. The capacity

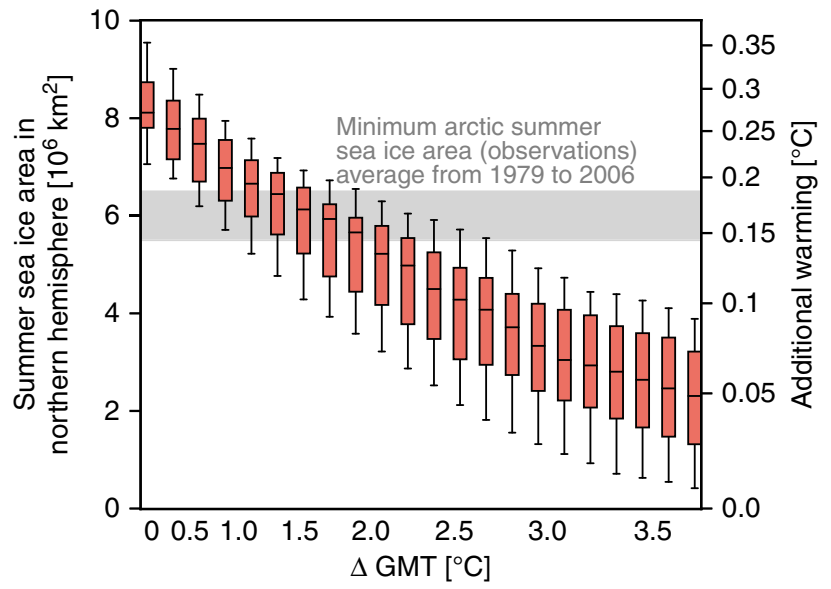

Fig. 4 Additional warming due to meltdown of Arctic summer sea ice. Box whiskers plot of global mean temperature $(\Delta G M T)$ versus Arctic summer sea ice area with error boxes (error bars) representing the interquartile range (full spread) of the ensemble at the according GMT over the CLIMBER-2 ensemble runs. The additional warming when the Arctic summer sea ice disappears is represented by a second $y$-axis computed via a least-square fit from the corresponding summer sea ice area. The relationship between summer sea ice area and additional warming is slightly nonlinear. This means that a doubling of the ice area does not quite translate into a doubling of the additional warming. The $x$-axis shows $\triangle \mathrm{GMT}$ above pre-industrial computed via a GMT- $\mathrm{CO}_{2}$ concentration leastsquare fit. The shaded area shows the mean Arctic sea ice area as observed by NERSC (Nansen Environmental \& Remote Sensing Center) from 1979 to 2006, where the uncertainty indicates one standard deviation:

$6.0 \pm 0.5 \times 10^{6} \mathrm{~km}^{2}$. to sustain water vapour is increased by $7 \%$ per degree of warming as can be computed using the Clausius-Clapeyron equation. Since the GMT is increasing through the removal of the cryosphere elements, the air can sustain more water vapour which then in turn leads to an additional warming. Together, the additional radiative perturbation of water vapour and lapse rate combine for approximately $30 \%$ of the complete radiative perturbation.

For the cloud feedbacks, the IPCC AR5 and newer studies hypothesised that the feedback from clouds is likely positive $e^{6,43}$ as we also find here. It is responsible for $15 \%$ of the total radiative perturbation.

Within our experimental setting, it can be expected that the radiative perturbation from albedo changes is very high due to the prescribed removal of the respective cryosphere element. However, the radiative perturbation related to different fast climate feedbacks such as water vapour, lapse rate and clouds also play an important role as drivers of additional warming. Together they account for more than $40 \%$ of the total radiative perturbation on average.

Similar investigations on the additional radiative perturbation from albedo changes have been performed for the removal of Arctic sea ice. For a removal of one month during summer an additional radiative perturbation of $0.3 \mathrm{~W} / \mathrm{m}^{2}$ is reported ${ }^{44}$ which is in good agreement with Flanner et al. (2011) ${ }^{45}$. We find a slightly higher value of $0.49 \mathrm{~W} / \mathrm{m}^{2}$ for albedo plus clouds value when the Arctic summer sea ice is removed (Table 1). This value probably is higher since we have low sea ice for approximately five months (Supplementary Fig. 3) in our perturbed experiments instead of one as in Hudson ${ }^{44}$, but parts of the deviation might also be due to the slightly different experimental setup.

In Supplementary Fig. 4a, we show the latitudinal distribution of the additional radiative perturbation at the top of the atmosphere. The contribution from albedo as well as from lapse rate and water vapour are higher in polar regions and thus contribute to polar amplification which is also apparent in the corresponding zonal mean surface warming (see Supplementary Fig. 4b). On the other hand, the additional cloud feedback does not strongly contribute to polar amplification in our simulations. These trends for clouds and albedo have also been found by other studies $^{36,46}$. Further studies mention that the lapse rate feedback plays a major role in polar amplification ${ }^{47}$. This seems to be the case here as well (see Supplementary Fig. 4a), but we can only make this statement for the combined feedbacks of lapse rate and water vapour since we do not separate them in our analysis.

\section{Discussion}

Our results concern short and long term effects on GMT due to the disintegration of cryosphere elements which experienced significant changes within the last decades and are likely to also change strongly in the future due to global warming.

Table 1 Drivers of warming as seen from the top of the atmosphere.

\begin{tabular}{ll} 
Cryosphere element & LR + WV $\left[\mathbf{W} / \mathbf{m}^{\mathbf{2}}\right]$ \\
\hline ASSI & $0.20(0.17-0.23)$ \\
GIS & $0.14(0.13-0.16)$ \\
WAIS & $0.05(0.04-0.05)$ \\
MG & $0.09(0.08-0.10)$ \\
All & $0.45(0.41-0.49)$
\end{tabular}

Clouds $\left[\mathbf{W} / \mathbf{m}^{\mathbf{2}}\right]$
$0.08(0.07-0.09)$
$0.06(0.05-0.07)$
$0.04(0.03-0.05)$
$0.04(0.03-0.05)$
$0.17(0.16-0.19)$

Albedo $\left[\mathrm{W} / \mathbf{m}^{\mathbf{2}}\right]$

$0.41(0.35-0.47)$

$0.22(0.20-0.25)$

$0.10(0.08-0.11)$

$0.16(0.14-0.17)$

$0.72(0.66-0.78)$
All changes $\left[\mathbf{W} / \mathbf{m}^{\mathbf{2}}\right]$

$0.69(0.59-0.79)$

$0.43(0.39-0.47)$

$0.18(0.16-0.21)$

$0.28(0.26-0.32)$

$1.35(1.22-1.46)$

ASSI Arctic summer sea ice, GIS Greenland Ice Sheet, WAIS West Antarctic Ice Sheet, MG Mountain glaciers.

The additional radiative perturbation for the fast climate feedbacks as evaluated in CLIMBER-2 at a global warming of $1.5^{\circ} \mathrm{C}$ above pre-industrial for disintegration of the respective element given as changes in $\mathrm{W} / \mathrm{m}^{2}$. The values are given as median and interquartile range (in brackets) of the ensemble. The "LR + WV" column represents the lapse rate and water vapour additional radiative perturbation column together as they are anti-correlated and thus not independent ${ }^{57}$. Note that the albedo forcing values refer to both, a forcing and a feedback. The forcing part is the removal of the cryosphere components and the feedback part comprises changes in vegetation and snow cover in response to the additional warming. 
On shorter time scales, the decay of the Arctic summer sea ice would exert an additional warming of $0.19^{\circ} \mathrm{C}\left(0.16-0.21^{\circ} \mathrm{C}\right)$ at a uniform background warming of $1.5^{\circ} \mathrm{C}(=400 \mathrm{ppm})$ above preindustrial. On longer time scales, which can typically not be considered in CMIP projections, the loss of Greenland and West Antarctica, mountain glaciers and the Arctic summer sea ice together can cause additional GMT warming of $0.43^{\circ} \mathrm{C}$ $\left(0.39-0.46^{\circ} \mathrm{C}\right)$. This effect is robust for a whole range of $\mathrm{CO}_{2}$ emission scenarios up to $700 \mathrm{pm}$ and corresponds to $29 \%$ extra warming relative to a $1.5^{\circ} \mathrm{C}$ scenario.

In fact, some feedbacks will also be at play before the complete disintegration of the large ice sheets, for instance due to increased ice-drainage from the Amundsen region in West Antarctica ${ }^{19,48,49}$. Furthermore, it has been shown for WAIS and GIS that transgressing their critical thresholds is likely not reversible due to hysteresis effects ${ }^{18,50,51}$.

The additional commitment to global warming that we study here represents a long-term, mean-field effect which is separated from possible direct interactions between the elements such as the freshwater input into the thermohaline circulation from the large ice sheets. In other words, the disintegration of the ice sheets has a direct increasing temperature impact on the GMT via the feedbacks quantified here.

\section{Methods \\ Earth system model. For our analysis, we use the Earth system model of inter mediate complexity (EMIC) CLIMBER-2 $2^{24,25}$ on a coarse spatial resolution of $10 \times 52^{\circ}$ (lat $\times$ lon) resolution. CLIMBER-2 includes a $2.5-\mathrm{D}$ dynamical-statistical atmosphere and a multi-basin, zonally averaged ocean model including sea ice as well as a dynamic model of the terrestrial biosphere. CLIMBER-2 also includes a model for ice sheets, a global carbon cycle model and an atmosphere surface interaction coupler, which are not used in this study since ice sheets and atmospheric $\mathrm{CO}_{2}$ are prescribed in our experiments. In CLIMBER-2, changes in the cloud fraction are possible. Apart from that, cloud top height can change following changes in the height of the tro- popause. The cloud optical thickness parameterisation includes a dependence on the cumulus cloud fraction in addition to a prescribed increase of optical thickness with latitude. With this representation of clouds, CLIMBER-2 is able to reproduce the planetary albedo as observed from CERES (see Supplementary Fig. 5) ${ }^{52}$. We benefit from the use of an EMIC as it is highly computationally efficient and allows for a systematic analysis of the impact of disintegration of the cryosphere elements on GMT. With CLIMBER-2 we are able to distinguish different feedbacks and are able to run a robustness analysis using systematic parameter studies. CLIMBER-2 is a good representative of other $\mathrm{EMICs}^{53}$.}

Model initialisation. In preparation of the model runs, we set up the ice sheets inbuilt in CLIMBER-2. For distinguishing the West and East Antarctic Ice Sheet, we created a mask based on the Antarctic drainage basins ${ }^{54}$. We also included a mountain glacier mask with data from the Randolph glacier inventory ${ }^{55}$. Since we are interested in the climatological behaviour of the disintegration of one or more of the cryosphere elements, we artificially change the setup of CLIMBER-2 depending on which element we remove: In case of WAIS and GIS, the topography of the ice sheet itself is removed together with the ice sheet as the height of the ice sheet is several thousand metres thick and thus might play an important role on the feedbacks. The albedo is replaced by the albedo of bare land or ocean (where appropriate) at first, but can then change freely into any kind of vegetation or snow cover during the simulation run. For our simulations, isostatic rebound is neglected.

For the Arctic summer sea ice and the mountain glaciers, the topography is not taken into account as either the height of the ice or the spacial extent of high thickness regions is very low. To remove the Arctic summer sea ice during the summer months (June, July and August: JJA), the surface covered by sea ice is darkened and the albedo in this region is replaced by the ocean albedo. With this procedure the energy conservation law is not violated since the ice is not just removed and still retains its function as boundary layer between ocean and atmosphere. Thus we are able to compute the effect of summer sea ice in an energetically self-consistent manner. Note that CLIMBER-2 is mass conserving. Our procedure is similar to the experimental setup of Blackport and Kushner ${ }^{30}$, who also reduce albedo values of the sea ice instantaneously. They do this for the whole year and all sea ice compared to our setup, where the albedo is changed only in the northern hemisphere in the summer months.

Model calibration. To emulate the behaviour of more complex general circulation models (GCMs) we created a model ensemble by perturbing several parameters with the target to cover the range of strength of the fast climate feedbacks found by
Soden and Held ${ }^{28}$ using an ensemble of GCMs. Equally, this could have been done with the feedbacks stated in the IPCC assessment report 5 (AR5), but changes in the reported feedback strengths are small except for the cloud feedback which is less well constrained in AR5 (see IPCC on page 819 for a direct comparison between AR5 values and the values given in Soden and Held ${ }^{28}$ ). Thus, our ensemble and our results can be expected to stay the same. The fast climate feedbacks include the water vapour, the lapse rate, the cloud and the albedo feedback. Each of our 39 ensemble members, that we end up with, is constructed from a pair of simulations: one control run at $280 \mathrm{ppm}$ and one perturbed run at a $\mathrm{CO}_{2}$ doubling of $560 \mathrm{ppm}$. We then compute the magnitude of the fast climate feedbacks between these pairs of runs (see Supplementary Fig. 1a). Here, we evaluate the feedbacks using the partial radiation perturbation method ${ }^{31,56}$. In this method partial derivatives of model top of the atmosphere radiation with respect to changes in model parameters (such as water vapour, lapse rate and clouds) are determined by diagnostically rerunning of the model radiation code.

The water vapour feedback added to the lapse rate feedback is supposed to lie in the range of $0.8-1.2 \mathrm{~W} / \mathrm{m}^{2} / \mathrm{K}$. These two feedbacks are evaluated together as they are correlated negatively ${ }^{28,57}$. The cloud feedback is supposed to range between 0.3 and $1.1 \mathrm{~W} / \mathrm{m}^{2} / \mathrm{K}$ and the albedo feedback between 0.2 and $0.45 \mathrm{~W} / \mathrm{m}^{2} / \mathrm{K}$. Furthermore, we put a constraint on the minimal summer sea ice cover in the northern hemisphere to $1.5-6.5 \mathrm{~km}^{2}$ (see Supplementary Fig. 1d). In Soden and Held $^{28}$, the albedo value is constraint to values between 0.2 and $0.4 \mathrm{~W} / \mathrm{m}^{2} / \mathrm{K}$, but in our calibration run, it is necessary to increase the upper limit to $0.45 \mathrm{~W} / \mathrm{m}^{2} / \mathrm{K}$ since vegetation shifts are considered and otherwise the ensemble gets distorted to small summer sea ice values in the control run.

On top of the fast climate feedbacks, we require each ensemble member (each pair of runs) to possess an equilibrium climate sensitivity above 1.5 and below $4.5^{\circ} \mathrm{C}$, where the equilibrium climate sensitivity is the global warming per doubling of atmospheric $\mathrm{CO}_{2}$ concentration (see Supplementary Fig. 1b). It is important to note that our ensemble members span the range from 2.0 to $3.75^{\circ} \mathrm{C}$. This leads to smaller temperature response ranges than the full range from 1.5 to $4.5^{\circ} \mathrm{C}$ would Furthermore, a last constraint is applied at a $\mathrm{CO}_{2}$ concentration of $280 \mathrm{ppm}$. The temperature difference between the runs with perturbed parameters and the reference run with unperturbed parameters (brackets in Supplementary Table 1) should be less or equal than $\pm 1.0^{\circ} \mathrm{C}$ (see Supplementary. Fig. 1c). After the application of all these constraints, we find 39 pairs of runs that match our restrictions.

For covering the uncertainty ranges of the feedbacks we perturb parameters (within their experimental uncertainty range) influencing lapse rate together with the water vapour, cloud and albedo feedbacks similarly to Deimling et al. ${ }^{57}$ (Supplementary Table 1). With this procedure, we are able to reconstruct the uncertainty ranges of the four fast climate feedbacks stated in Soden and Held ${ }^{28}$ fairly well.

Uncertainty estimates. We used these 39 calibrated runs, which also represent the uncertainty of our results, as initialisation for our large-scale ensemble simulations For each of the cryosphere elements, i.e., WAIS, GIS, Arctic summer sea ice and mountain glaciers, as well as all together, we performed the following experiments: (i) Control runs: the respective cryosphere element(s) is/are kept and (ii) experiment runs: removed cryosphere element(s).

We performed the experiments in (i) and (ii) for different atmospheric $\mathrm{CO}_{2}$ concentrations as external forcing. We chose the $\mathrm{CO}_{2}$ concentration parameter since it is the one which is most probably increasing in future climate change scenarios. Each of the experiments is performed as a long term equilibrium run for 10,000 simulation years with today's boundary conditions, i.e., astrophysical parameters like eccentricity and obliquity, and fixed $\mathrm{CO}_{2}$ concentration. The results are taken as the mean over the last 4000 simulated years since this cancels out minor fluctuations in the equilibrium state. In the end we subtract the experimental run (ii) from the control run (i) to retrieve the temperature difference. Since we are reporting these differences between perturbed (experimental) and control run throughout the main manuscript, the uncertainties given as interquartile ranges are small, also compared to the calibration (see Supplementary Fig. 1). This means that our CLIMBER-2 ensemble is robust against the same perturbations in the cryosphere components. We constructed our ensemble aiming at covering a range of sensitivities and different strengths of the feedbacks by the variation of the parameters in Supplementary Table 1.

\section{Data availability}

The data that support the findings of this study are available from the corresponding author upon reasonable request.

\section{Code availability}

There is no comprehensively documented code for the Earth system model CLIMBER-2 available owing to a lack of comprehensive technical description, but the code is available upon request from M.W.

Received: 22 January 2019; Accepted: 17 September 2020; Published online: 27 October 2020 


\section{References}

1. Stroeve, J. C. et al. The arctic's rapidly shrinking sea ice cover: a research synthesis. Clim. Change 110, 1005-1027 (2012).

2. Gardner, A. S. et al. A reconciled estimate of glacier contributions to sea level rise: 2003 to 2009. Science 340, 852-857 (2013).

3. Zwally, H. J. et al. Greenland ice sheet mass balance: distribution of increased mass loss with climate warming; 2003-07 versus 1992-2002. J. Glaciol. 57, 88-102 (2011).

4. Khan, S. A. et al. Sustained mass loss of the northeast greenland ice sheet triggered by regional warming. Nat. Clim. Change 4, 292-299 (2014).

5. Shepherd, A. et al. Mass balance of the antarctic ice sheet from 1992 to 2017. Nature 558, 219-222 (2018).

6. Stocker, T. F. et al. Climate change 2013: The Physical Science Basis. Contribution of Working Group I to the Fifth Assessment Report of the Intergovernmental Panel on Climate Change 1535 (Cambridge University Press, 2013).

7. Overland, J. E. \& Wang, M. When will the summer arctic be nearly sea ice free? Geophys. Res. Lett. 40, 2097-2101 (2013).

8. Niederdrenk, A. L. \& Notz, D. Arctic sea ice in a $1.5 \mathrm{c}$ warmer world. Geophys. Res. Lett. 45, 1963-1971 (2018).

9. Notz, D., Haumann, F. A., Haak, H., Jungclaus, J. H. \& Marotzke, J. Arctic seaice evolution as modeled by max planck institute for meteorology's earth system model. J. Adv. Modeling Earth Syst. 5, 173-194 (2013).

10. Leclercq, P. W., Oerlemans, J. \& Cogley, J. G. Estimating the glacier contribution to sea-level rise for the period 1800-2005. Surv. Geophys. 32, 519 (2011).

11. Marzeion, B., Jarosch, A. \& Hofer, M. Past and future sea-level change from the surface mass balance of glaciers. Cryosphere 6, 1295 (2012)

12. Marzeion, B., Kaser, G., Maussion, F. \& Champollion, N. Limited influence of climate change mitigation on short-term glacier mass loss. Nat. Clim. Change 8, 305-308 (2018).

13. Christian, J. E., Koutnik, M. \& Roe, G. Committed retreat: controls on glacier disequilibrium in a warming climate. J. Glaciol. 64, 675-688 (2018).

14. Steffen, W. et al. Trajectories of the earth system in the anthropocene. Proc. Natl Acad. Sci. 115, 8252-8259 (2018).

15. Clark, P. U. et al. Consequences of twenty-first-century policy for multimillennial climate and sea-level change. Nat. Clim. Change 6, 360-369 (2016).

16. Levermann, A. \& Winkelmann, R. A simple equation for the melt elevation feedback of ice sheets. Cryosphere 10, 1799-1807 (2016).

17. Box, J. et al. Greenland ice sheet albedo feedback: thermodynamics and atmospheric drivers. Cryosphere 6, 821-839 (2012).

18. Robinson, A., Calov, R. \& Ganopolski, A. Multistability and critical thresholds of the greenland ice sheet. Nat. Clim. Change 2, 429-432 (2012).

19. Favier, L. et al. Retreat of pine island glacier controlled by marine ice-sheet instability. Nat. Clim. Change 4, 117-121 (2014).

20. Winkelmann, R., Levermann, A., Ridgwell, A. \& Caldeira, K. Combustion of available fossil fuel resources sufficient to eliminate the antarctic ice sheet. Sci. Adv. 1, e1500589 (2015).

21. Masson-Delmotte, V. et al. Global Warming of $1.5{ }^{\circ} \mathrm{C}$ : An IPCC Special Report on the Impacts of Global Warming of $1.5^{\circ} \mathrm{C}$ Above Pre-industrial Levels and Related Global Greenhouse Gas Emission Pathways, in the Context of Strengthening the Global Response to the Threat of Climate Change, Sustainable Development, and Efforts to Eradicate Poverty (World Meteorological Organization Geneva, Switzerland, 2018).

22. Lenton, T. M. et al. Tipping elements in the earth's climate system. Proc. Natl Acad. Sci. 105, 1786-1793 (2008)

23. Schellnhuber, H. J., Rahmstorf, S. \& Winkelmann, R. Why the right climate target was agreed in paris. Nat. Clim. Change 6, 649 (2016).

24. Petoukhov, V. et al. Climber-2: a climate system model of intermediate complexity. part i: model description and performance for present climate. Clim. Dyn. 16, 1-17 (2000).

25. Ganopolski, A. et al. Climber-2: a climate system model of intermediate complexity. part ii: model sensitivity. Clim. Dyn. 17, 735-751 (2001).

26. Ganopolski, A. \& Brovkin, V. Simulation of climate, ice sheets and co2 evolution during the last four glacial cycles with an earth system model of intermediate complexity. Climate 13, 1695-1716 (2017).

27. Ganopolski, A., Winkelmann, R. \& Schellnhuber, H. J. Critical insolation- $\mathrm{CO}_{2}$ relation for diagnosing past and future glacial inception. Nature 529, 200-203 (2016).

28. Soden, B. J. \& Held, I. M. An assessment of climate feedbacks in coupled ocean-atmosphere models. J. Clim. 19, 3354-3360 (2006).

29. Meehl, G. A. et al. Context for interpreting equilibrium climate sensitivity and transient climate response from the cmip6 earth system models. Sci. Adv. 6, eaba1981 (2020).

30. Blackport, R. \& Kushner, P. J. The transient and equilibrium climate response to rapid summertime sea ice loss in ccsm4. J. Clim. 29, 401-417 (2016).
31. Bony, S. et al. How well do we understand and evaluate climate change feedback processes? J. Clim. 19, 3445-3482 (2006)

32. Golledge, N. R. et al. Global environmental consequences of twenty-firstcentury ice-sheet melt. Nature 566, 65-72 (2019).

33. Bronselaer, B. et al. Change in future climate due to antarctic meltwater. Nature 564, 53-58 (2018).

34. Swingedouw, D. et al. Antarctic ice-sheet melting provides negative feedbacks on future climate warming. Geophys. Res. Lett. 35 https://doi.org/10.1029/ 2008GL034410 (2008)

35. Fichefet, T. et al. Implications of changes in freshwater flux from the greenland ice sheet for the climate of the 21st century. Geophys. Res. Lett. 30 https://doi.org/10.1029/2003GL017826 (2003).

36. Pithan, F. \& Mauritsen, T. Arctic amplification dominated by temperature feedbacks in contemporary climate models. Nat. Geosci. 7, 181-184 (2014).

37. Screen, J. A. \& Simmonds, I. The central role of diminishing sea ice in recent arctic temperature amplification. Nature 464, 1334-1337 (2010).

38. Fischer, $\mathrm{H}$. et al. Palaeoclimate constraints on the impact of $2 \mathrm{c}$ anthropogenic warming and beyond. Nat. Geosci. 11, 474 (2018).

39. Dutton, A. et al. Sea-level rise due to polar ice-sheet mass loss during past warm periods. Science 349, aaa4019 (2015).

40. Lord, N. S. et al. Emulation of long-term changes in global climate: application to the late pliocene and future. Climate 13, 1539-1571 (2017).

41. Lunt, D. J. et al. On the causes of mid-pliocene warmth and polar amplification. Earth Planet. Sci. Lett. 321, 128-138 (2012).

42. Notz, D. \& Stroeve, J. Observed arctic sea-ice loss directly follows anthropogenic $\mathrm{CO}_{2}$ emission. Science 354, 747-750 (2016)

43. Zelinka, M. D., Randall, D. A., Webb, M. J. \& Klein, S. A. Clearing clouds of uncertainty. Nat. Clim. Change 7, 674-678 (2017).

44. Hudson, S. R. Estimating the global radiative impact of the sea ice-albedo feedback in the arctic. J. Geophys. Res.: Atmos. 116, https://doi.org/10.1029/ 2011JD015804 (2011).

45. Flanner, M. G., Shell, K. M., Barlage, M., Perovich, D. K. \& Tschudi, M. Radiative forcing and albedo feedback from the northern hemisphere cryosphere between 1979 and 2008. Nat. Geosci. 4, 151-155 (2011).

46. Goosse, H. et al. Quantifying climate feedbacks in polar regions. Nat. Commun. 9, 1-13 (2018).

47. Stuecker, M. F. et al. Polar amplification dominated by local forcing and feedbacks. Nat. Clim. Change 8, 1076-1081 (2018).

48. Joughin, I. \& Alley, R. B. Stability of the west antarctic ice sheet in a warming world. Nat. Geosci. 4, 506-513 (2011)

49. Joughin, I., Smith, B. E. \& Medley, B. Marine ice sheet collapse potentially under way for the thwaites glacier basin, west antarctica. Science 344, 735-738 (2014).

50. Pollard, D. \& DeConto, R. M. Modelling west antarctic ice sheet growth and collapse through the past five million years. Nature 458, 329-332 (2009).

51. Pollard, D. \& DeConto, R. M. Hysteresis in cenozoic antarctic ice-sheet variations. Glob. Planet. Change 45, 9-21 (2005).

52. Wielicki, B. A. et al. Clouds and the earth's radiant energy system (ceres): An earth observing system experiment. Bull. Am. Meteorol. Soc. 77, 853-868 (1996).

53. Petoukhov, V. et al. EMIC Intercomparison Project (EMIP-CO 2 ): comparative analysis of emic simulations of climate, and of equilibrium and transient responses to atmospheric $\mathrm{CO}_{2}$ doubling. Clim. Dyn. 25, 363-385 (2005)

54. Zwally, H. J., Giovinetto, M. B., Beckley, M. A. \& Saba, J. L. Antarctic and Greenland Drainage Systems (GSFC Cryospheric Sciences Laboratory, 2012).

55. RGI Consortium. Randolph Glacier Inventory-A Dataset of Global Glacier Outlines, Version 6.0: Technical Report, Global Land Ice Measurements from Space, Colorado, USA. Digital Media. https://doi.org/10.7265/N5-RGI-60 (2017).

56. Wetherald, R. \& Manabe, S. Cloud feedback processes in a general circulation model. J. Atmos. Sci. 45, 1397-1416 (1988).

57. von Deimling, T. S., Held, H., Ganopolski, A. \& Rahmstorf, S. Climate sensitivity estimated from ensemble simulations of glacial climate. Clim. Dyn 27, 149-163 (2006)

\section{Acknowledgements}

This work has been carried out within the framework of the IRTG 1740/TRP 2015/ 50122-0 funded by DFG and FAPESP. N.W. and R.W. acknowledge their support. M.W acknowledges support from the BMBF through the project PalMod. J.F.D. is grateful for financial support by the Stordalen Foundation via the Planetary Boundary Research Network (PB.net), the Earth League's EarthDoc programme, and the European Research Council Advanced Grant project ERA (Earth Resilience in the Anthropocene; grant ERC 
2016-ADG-743080). We are thankful for support by the Leibniz Association (project DominoES). The authors gratefully acknowledge the European Regional Development Fund (ERDF), the German Federal Ministry of Education and Research and the Land Brandenburg for supporting this project by providing resources on the high performance computer system at the Potsdam Institute for Climate Impact Research.

\section{Author contributions}

N.W., M.W., J.F.D. and R.W. designed the study and wrote the text including revisions. N.W. conducted the model simulation runs and prepared the figures. M.W. designed the model calibration and prepared CLIMBER-2 for simulations.

\section{Funding}

Open Access funding enabled and organized by Projekt DEAL.

\section{Competing interests}

The authors declare no competing interests.

\section{Additional information}

Supplementary information is available for this paper at https://doi.org/10.1038/s41467020-18934-3

Correspondence and requests for materials should be addressed to N.W. or R.W.
Peer review information Nature Communications thanks Jan Sieber and the other, anonymous, reviewer(s) for their contribution to the peer review of this work. Peer reviewer reports are available.

Reprints and permission information is available at http://www.nature.com/reprints

Publisher's note Springer Nature remains neutral with regard to jurisdictional claims in published maps and institutional affiliations.

(c) (i) Open Access This article is licensed under a Creative Commons Attribution 4.0 International License, which permits use, sharing, adaptation, distribution and reproduction in any medium or format, as long as you give appropriate credit to the original author(s) and the source, provide a link to the Creative Commons license, and indicate if changes were made. The images or other third party material in this article are included in the article's Creative Commons license, unless indicated otherwise in a credit line to the material. If material is not included in the article's Creative Commons license and your intended use is not permitted by statutory regulation or exceeds the permitted use, you will need to obtain permission directly from the copyright holder. To view a copy of this license, visit http://creativecommons.org/ licenses/by/4.0/.

(C) The Author(s) 2020 